\title{
REFERENCE:
}

Niven, E., Roy, D. E., Schaefer, B. A., Gasquoine, S. E., \& Ward, F. A. (2011, online early). Making research real: Embedding a longitudinal study in a taught research course for undergraduate nursing students. Nurse Education Today (0) doi:10.1016/j.nedt.2011.10.024

\section{MAKING RESEARCH REAL: EMBEDDING A LONGITUDINAL STUDY IN A TAUGHT RESEARCH COURSE FOR UNDERGRADUATE NURSING $\underline{\text { STUDENTS }}$}

\begin{abstract}
$\underline{\text { ABSTRACT }}$
Learning how and why scholarly research underpins and informs professional nursing practice is a continual challenge for undergraduate nursing students. They find the language and methods of research to be unfamiliar and unsettling. The work of educators thus becomes the process of breaking down barriers to students' understanding of research processes and application. Such work is increasingly important in the current era of evidence based practice, where students must be competent in sourcing, critiquing and applying research to meet real clinical questions. In response, as lecturers who taught the course, Research for Health Professionals, we have reinvented how research is taught to second year undergraduate students. This article outlines our creative approach to facilitate students learning research theory and methodology by conducting a "real-life" research study in a local retirement community.
\end{abstract}

\section{INTRODUCTION}

How do we know learning is occurring in our classrooms? Nursing lecturers teaching Research for Health Professionals considered this after students expressed concern about their inability to achieve the course's learning outcomes (Table 1). The outcomes seemed reasonable to us, but students found descriptions of research components vague, meaningless, and difficult to comprehend. The perceptions of our students were not unique; they reflected a well-documented phenomenon (Perkins, 1992, Burrows \& Baillie, 1997, Taylor \& Muncer, 2000).

Student concerns about achieving the required outcomes became apparent in two ways. First, the students' end-of-course evaluations contained negative comments about their learning. Students wrote about their difficulty understanding research terminology, inability to grasp research concepts, and concerns over the relevance research had to their nursing practice. Second, the final course grades indicated students' performance to be far below what was expected. These findings indicated that we needed to reconsider the content and delivery of the course and re-establish it as a viable part of the Bachelor of Nursing $(\mathrm{BN})$ curriculum.

Dirkx (1997) writes about the challenges educators face in trying to make education meaningful. "To truly grasp the holistic nature of learning in adulthood, its mystery and messiness, we need a way of seeing that keeps learning embedded in the concreteness of everyday life” (p. 81). Passionate about the relevance research has to 
real world nursing we took up the challenge. We explored ways to reshape the course in order that students might experience research as a "real-life" learning activity.

Knowing the research course needed a complete rewrite, we sought inspiration from Schön's $(1983,1987)$ theory of developing knowledge-in-action through reflection and Kolb’s (1984) experiential learning theory. McLaughlin et al. (2006) subsequently wrote about the need to assist learners with their professional role development, which affirmed our process. They suggested that this required engagement of students on both emotional and intellectual levels. In other words, to assist our students to become consumers of research we needed to make learning exciting, interesting, and true-to-life. To accomplish this would require a research course that actively engaged students in learning.

Nursing educators around the world know how to create hands-on, "real-life" learning experiences using simulation exercises and clinical placements in health care facilities to make student learning relevant and meaningful. Thus, we decided to introduce a "real" research experience into the research course, and since 2005 students enrolled in the course have participated in a research project embedded in their course.

This article recounts our experience of creating and delivering the revised research course in the hope that sharing it might inspire others to do likewise, just as reports of teaching innovations of international colleagues (for example Ravert et al., 2004, Brosnan et al., 2005) gave us direction in planning and implementing the changes we made to our programme. It includes a historical review of nursing research in New Zealand (NZ) and a brief review of our educational approaches for teaching research. We provide a description of the revised research course; a review of the steps taken to implement course changes; student reactions to the new course curriculum; and our reflection on the educational outcomes.

\section{$\underline{\text { BACKGROUND }}$}

Wood (2002) outlines a long history of scholarly enquiry by nurses in NZ. The scholarly nature of this enquiry was enhanced moving nursing education from apprentice-style training within hospitals to the tertiary education sector in the 1970s. This led to diploma-level preparation for registered nurses (RN). An emphasis on research 'consumership' and practice based on evidence reflected a growing awareness amongst health professionals of its importance (Courtney, 2005) and was further supported in NZ by the change to degree-level programmes for RN preparation in the 1990s.

The research imperative has been emphasised more recently by the NZ Health Practitioners Competence Assurance Act (2003) that resulted in detailed competencies for the RN scope of practice being developed and approved by the Nursing Council of NZ (NCNZ) (2007). One competency states that nursing care should be "supported by nursing knowledge and evidence based research" (NCNZ, 2007, p. 4) which aligns expectations of NZ registered nurses with colleagues internationally (Gray, 2010).

The evolution of research teaching at our tertiary institution (Unitec) mirrors the history of scholarly inquiry in NZ. A diploma of nursing was first offered in 1986, 
with a research paper completed in the programme's third year. While this course focused primarily on the development of skills for research consumership, students were required to 'utilise the research process' through completion of research projects. These often consumed a disproportionate amount of teaching and learning time. Projects were often too complex, while topics trivial. Following a curriculum review in 1993 this requirement was dropped.

Our first degree programme was offered 1994 and the focus moved to 'knowledge'; how it is identified, challenged, created, and used. There were 'theory and research' courses within each of the three years of the programme. By the late 1990s in the international context of nursing, there was much written about the so-called theorypractice gap (Rolfe, 1997). Mindful of this, and in response to student feedback, decisions were made during the degree programme's first review to eliminate the stand-alone third-year research course and integrate learning outcomes across all third-year courses. The revised curriculum was offered for the first time in 1998. It included a first-year course that focused on the basis of nursing knowledge and incorporated an introduction to research processes. The second-year course focused on research methods to a level that would enable the students to comprehend and critique scholarly research findings and apply that knowledge within their third year of study and subsequent professional practice.

\section{Motivation for Change}

Despite our best efforts, the revised curriculum remained problematic. Student resistance and negative feedback about what they learned in the research course continued to be reflected in low or failing grades. After the completion of the course in 2004, formal student feedback was collected using the standard institutional end-ofcourse survey tool, 'Student Evaluation of Quality' (SEQUAL) which was administered independently by Unitec's corporate office. This ensured student confidentiality and the validity of the course evaluations. Student participation was voluntary.

The mean score of students' overall satisfaction with the quality of the course was 2.23 on a scale of $5(n=44)$. The anonymised student comments were of most concern. Students felt the course material was "taught over their heads". The language of research was found to be abstract and they wanted us to "bring the level of teaching down to undergraduate level". They suggested the subject was "dry" and they were "struggling to grasp the concept of research". One student suggested lecturers "use more day-to-day examples when teaching". Another stated they "had difficulty linking knowledge with clinical practice". The final comment on the survey summed up their concerns, "the course has a small percent of relevance and lacks connection to real nursing practice”.

In addition to this formal feedback, we considered the students' academic feedback reflected in their end-of-course grades $(n=78)$. The mean grade was $\mathrm{C}+$; the mode $\mathrm{C}$. Although a bell curve was achieved, there were only 3 (2.3\%) A's and a disproportionate number of failing grades; 16 (12.5\%). The disparity between the number of students who excelled and the high failure rate was significant and demonstrated an imbalance in achievement that was not apparent in other BN courses. 
Dissatisfaction with the course was growing and we were concerned about the widening knowledge gap between the theory and practice of research. It seemed the students' main focus was about learning what would be in the exam rather than how research should inform their professional practice.

It was within this context that we were challenged to develop a new approach to teaching nursing research that would capture student interest, improve their learning and encourage their use of research to inform their practice. Equipping the students with the knowledge and skills for research consumership remained our imperative and a return to students completing their own research project not pedagogically sound. However, we recognised the potential value to student learning of 'doing' compared with 'learning about' research.

\section{OPPORTUNITIES}

In addition to furthering the research knowledge of the students we saw a revision of the course as an opportunity to work with the local community's well elderly. We were aware that students' perceptions of the older adult were limited to their experience of working with them as patients in an acute-care setting (McKinlay \& Cowan, 2003, McLafferty \& Morrison, 2004). We saw the opportunity to change this largely negative perception by forming a research collaboration with a community agency that served the well elderly. The agency was planning to explore how technology could support older adults in their homes, providing the opportunity for a collaborative research partnership.

Thus, fuelled by the findings of the literature review to make the research experience "real” (for example Schon, 1983, 1987, McCaugherty, 1991, Tinto \& Russo, 1994, Dirkx, 1997, Ravert et al., 2004, Brosnan et al., 2005), inspired by the needs of the retirement community for information, and supported by our institution's desire to build relationships with the local community, we seized the opportunity to rework the course.

The idea to establish a 5-year longitudinal study with the older adult community and use that experience as a teaching forum for students emerged. Having students participating in research as 'research assistants' for data collection would enable us to embed a study within the academic course. The findings of the research, which aimed to explore the use of technology in the lives of members of the retirement community, would be used to both inform the older adults' interest regarding the use and development of technology in their community and health care providers, especially those in the retirement/older adult sector, about this emerging phenomenon. Course lecturers were the named investigators, taking responsibility for all processes and decision-making during the study, including development of the questionnaires, information sheets and consent forms.

\section{EMBEDDING THE STUDY}

As we planned the new format and delivery of the course, we knew there were some important challenges to be addressed. First, we wanted to be sure students stayed engaged and interested in the course content from the outset. If students knew that the content of each lecture and tutorial would be foundational to their experience in 
collecting data for the research study, they might begin to see the relevance of the information being provided. Therefore, we continually referred to the study for examples to support their learning in the weekly lectures and tutorials. Student enquiries and need for explanation about why they were to do something in a particular way also informed the conduct of the study.

We had to be mindful of the students' workload in other courses. Throughout the course, we used processes that maximised student learning with an economy of effort. For example, for ease of use, course reading requirements were online and linked to databases, and assignments came with keywords to facilitate literature searches. We encouraged peer collaboration for assignment preparation and in planning for data collection. Working in pairs, students were able to share the workload and support each other's learning during the phases of hands-on research tasks.

We had to comply with the requirements of each institution's regulations governing research; using students as research assistants added complexity. Both agencies, the retirement community's governing board and our institution's research ethics committee, in granting their approval required us to respect the rights of the residents who volunteered to participate and maintain the integrity of their privacy and security, their data and the research outcomes. Special procedures were implemented to ensure that this occurred and included notifying the complex at the beginning of the teaching semester of the days lecturers and students would be onsite; specific instructions to the students about introducing themselves to residents; the opportunity to practice data collection techniques in tutorials; wearing 'visitor' name badges (issued by the main office) while at the complex and close monitoring of student whereabouts via text messages throughout the data collection visits. Another challenge was that the research study produced real data requiring genuine processing within existing workloads. We reported the immediate research findings to the governing board of the retirement community annually, with cumulative analysis and reporting on completion of the 5-year longitudinal study.

\section{$\underline{\text { ACTIONING DATA COLLECTION }}$}

Each year lecturers undertook several tasks prior to data collection at the retirement community. Clear communication about the research project was shared with the retirement community's residents' committee via a weekly newsletter. Information sheets were distributed and residents interested in volunteering contacted a member of the retirement community who acted as the liaison with us. The residents' committee advised us on the best times for data collection interviews to occur so as not to interfere with meals, afternoon rest period, or common shopping times. They also discussed with us the length, style, and content of the interview along with the type of data gathering tools and interview methods that would be appropriate for this population. Discussion of this preparatory phase with students enabled them to appreciate that ethical practice permeates all research activities.

\section{$\underline{\text { Students as research assistants }}$}

Student preparation for data collection occurred during tutorials and included instructions on the importance of contacting participants prior to the interview, ways to practice the interview questions, and how to use the data gathering tools and audio- 
recorder. Advice about professional dress and cultural courtesies extended to NZ's older adults were also reviewed.

We reviewed with students a variety of possible challenges that might occur when they were in the community. Examples included possible responses to unexpected situations, such as, how to relate to an elderly NZ war veteran who once considered a student's country of origin to be "enemy territory"; how students whose first language was not English could better make themselves understood to a resident with a hearing impairment; what they should do if a resident cancelled the interview, or what to do if the resident invited them to stay for tea.

Students were paired with a fellow student. Sharing the experience with another person was seen as an active way of reinforcing what was learned. Students for whom speaking English was challenging were paired with a confident English speaker and encouraged to 'deliver' at least part of the questionnaire. The day before a visit, the pair was told the time of the interview session, and required to confirm the interview appointment with the participant. Students arrived at the retirement community and registered with their lecturer thirty minutes ahead of the scheduled interview. After registering, the student-pair was given a map to locate the resident's house, an audiorecorder, consent and interview forms. They were reminded of methods to ensure the confidentiality and security of their research data after collection.

Student-pairs then proceeded to the participant's home and conducted their hour-long interview. The interview procedures included obtaining signed consent from the participating resident, completion of a written demographic survey and questionnaire, and participation in a semi-structured recorded interview. When finished, the students returned to the central meeting place for debriefing with lecturers, and handed over all data for safe-keeping. Student-pairs then reflected on the experience and made notes about what had transpired, a process Kolb (1984) attests is most valuable in promoting learning. A report on their field experience was written as a summative assessment point for the course and contributed to refining the process for the cohort of students who would enrol in the research course the following year.

Both qualitative and quantitative data were collected using questionnaires developed and piloted by lecturer-investigators in collaboration with the residents' committee. Qualitative data were gathered using set interview questions with responses audiorecorded. After the visit, students reviewed and transcribed a small section of the conversations. They were required to listen to the interview several times, noting the key points or themes raised by the participants. At a subsequent tutorial, key points and themes were collated; students thereby assisting in the analysis of their data. All tutorial groups were able to identify several themes from the data putting into practice what had been taught in lectures.

The collection of the quantitative data was facilitated through the use of two survey tools; a demographic survey and a Likert-scaled questionnaire. Students either gave the forms to the residents to read and complete, or they read the questions to them and entered the participant's response by hand. Survey data were discussed in tutorials and students had the opportunity to enter data electronically into prepared spreadsheets. While only a minimal amount of descriptive quantitative data was collected by each student-pair, the aggregated data in each tutorial group was 
sufficient to provide students with an opportunity to undertake some small-scale data manipulation. They began to see patterns emerging, from which they drew preliminary conclusions and meaning. In this way, they were able to use collected data to discover how relationships between age, gender, and length of time at the retirement complex could be used to better understand the study population.

The students observed how we collected the audio-recordings, questionnaires and consent forms at the conclusion of the interviews. This process which ensured security, privacy and anonymity for the participants demonstrated to students approved ethical procedures; contributing to their growing experiential knowledge of research.

Following data collection and initial analysis by the students, formal analysis was performed by lecturer-investigators. Although these results will be reported separately, preliminary findings are given (Table 2).

\section{STUDENT RESPONSES}

Overall response by students to the revised curriculum was very positive. For 2005 (following the first year of the new course) the mean SEQUAL score measure (described above) of students' overall satisfaction with the quality of the course was $3.23(n=90)$ on a scale of 5 compared to the 2004 mean of $2.23(n=44)$. Anonymised student comments included: "enjoying the practical research". They called the field research "fun" and a "balance between real-world and theory", "extended my knowledge on research", "The theory came out clear, after we did the practical part.", "Being part of a research study worked well to take the dryness of the subject away.", "Actually being part of the research project made it much nicer and meant that handson learning happened too". Others acknowledged that the course helped prepare them for master's level studies. The 'real-work' aspect "engrossed" the students in research and made them enthusiastic learners.

The assessment points used to measure academic competencies in both 2004 and 2005 consisted of two written assignments and one final examination. The weighting of the final examination was decreased from $60 \%$ (2004) to 50\% (2005), thus, shifting the emphasis on student performance from the examination to the written assignments, which focussed on knowledge related to the processes of the research study and students' reflection on their contribution. The mean end-of-course grade for the 2005 semester was B-, the mode was B-; a bell curve was achieved. In addition, there were six A's (50\% increase over 2004) and only 2 failing grades (compared to 16 in 2004). The number of failures compared to the number of students who received excellent marks had improved significantly from 2004. The new course's assessment data indicated to us that there was a substantial positive shift in student engagement with their learning. The positive shift in student engagement and achievement as reflected in assessment data has continued for subsequent cohorts.

\section{$\underline{\text { REFLECTION }}$}

In 2009 students collected the final data for the 5-year longitudinal study at the retirement community. Over this period more than four-hundred students participated. Reflecting on this, we remember the highlights this experience has had on their 
learning and understanding of research. We are pleased and proud of the turnaround in student perception of their learning, the engaged way in which learning occurs, and the improved measurable outcomes as exemplified in improved student grades.

Another outcome of this experience has been the changed perception of students regarding the daily life of older adults in NZ. In their prior education and lifeexperience, many students had little to do with older adults who were living independently. By virtue of this "lived" research experience, students learned about the independent nature and lifestyle of this older population and no longer consider them as being infirm or overly dependent.

We are pleased with our ability to match ninety-plus students with some forty-five participants and get them to the right person, at the right time, on the right day for each year of the study. The oversight of the collection, analysis, and secure storage of data has, however, created its own set of challenges. We have learned that it takes four lecturers three days in the field and many hours of data entry and analysis to make this experience meaningful to the students and the residents of the retirement community. The burden of conducting scholarly research in conjunction with teaching continues to challenge us as data analysis, interpretation and writing take place around busy teaching schedules.

Over the years, we made changes to improve the processes of the study. We decreased the number of students going to the retirement community on one day, eventually spreading the field visits over three days. As with all new research tools, the consent forms, interview schedule, and questionnaires were refined for clarity and ease of use. Review of these changes was coordinated with the residents' committee and approved by our institution's research ethics committee.

\section{CONCLUSION}

We knew we had succeeded in our efforts to change student perceptions about learning research when we read a SEQUAL comment from one student who had completed the revised research course.

The challenges for me began early as I found it complicated to grasp the concept of what we were supposed to produce in our first assignment. I can see I made it difficult for myself by automatically thinking research was going to be a difficult subject. This has taught me that I need to go in with an open mind and tackle tasks one step at a time.

This article has described the process of students coming to know nursing research by participating in a learning experience based on participation and active learning. By teaching research as a "lived" experience, we changed student perceptions about nursing research from being a subject "difficult" to learn into one that can be learned “one step at a time”. Review of academic performance demonstrated students' improved learning about research theory and methodology. Additionally, the students' interactions with older adults deepened their appreciation of the ways older adults live in today's technical world. 
In 2010 a new research project to support students in learning the principles of research by involving them as research assistants began. This project partners nursing students with clinical colleagues to explore an issue identified by the 'stroke' service of a large acute-care facility. Having gained ethical approval, lecturers are once again delivering lectures and tutorials that equip students with the necessary knowledge to conduct themselves appropriately as research assistants while preparing them to become critical consumers of research. Participating in another research partnership that mirrors that described above is another measure of our success with such an undertaking.

If as a profession we are committed to registered nurses being research consumers and to basing their practice on evidence, academic departments such as ours need to approach the teaching of the principles of ethical, practice-focussed research in the same way we do the practice competencies expected by nursing registration authorities. While the revised Research for Health Professionals course is documented as a 'theory' course with no practice hours of learning associated with it, our experience of embedding research supports the notion that it is the experience in a practice setting of conducting aspects of research that make the theoretical concepts associated with research meaningful for learners, with the knowledge "more likely to be retained and applied in subsequent clinical situations” (Henderson, 2011). 
Table 1: Research for Health Professionals: Course Structure and Learning Outcomes

\begin{tabular}{|l|l|}
\hline & COURSE AIM \\
\hline & $\begin{array}{l}\text { To enable the student to develop the skills and knowledge } \\
\text { appropriate to beginning research consumership. }\end{array}$ \\
\hline & COURSE LEARNING OUTCOMES \\
\hline 1. & Examine the research process \\
\hline 2. & Identify and explore clinical problems amenable to research \\
\hline 3. & Examine research methods used in healthcare \\
\hline 4. & $\begin{array}{l}\text { Practice data collection and analysis methods from a variety of } \\
\text { approaches }\end{array}$ \\
\hline 5. & $\begin{array}{l}\text { Examine ethico-legal issues relating to research in health and } \\
\text { research } \\
\text { utilisation }\end{array}$ \\
\hline 6. & $\begin{array}{l}\text { Evaluate current research findings and apply them to professional } \\
\text { healthcare practice }\end{array}$ \\
\hline 1. & CONTENT/TOPICS \\
\hline 2. & Research Process \\
\hline 3. & Sources of research problems \\
\hline 4. & Ratching problem and method \\
\hline 5. & Literature/database searches \\
\hline 6. & Ethico-legal issues \\
\hline 7. & Sampling \\
\hline 8. & Data collection and analysis \\
\hline 9. & Report writing and critical review \\
\hline 10. & Research utilisation \\
\hline &
\end{tabular}

Table 2: Preliminary findings of the embedded research study, "the place of technology in the lives of residents of a retirement community".

\begin{tabular}{|c|l|}
\hline & $\begin{array}{l}\text { THE PLACE OF TECHNOLOGY - PRELIMINARY } \\
\text { FINDINGS }\end{array}$ \\
\hline 1. & $\begin{array}{l}\text { Male family members have a significant role of in influencing } \\
\text { what technology older adults acquire. }\end{array}$ \\
\hline 2. & $\begin{array}{l}\text { Personal computers rank high on the list of items required by the } \\
\text { well older adult. There is clear recognition that computers are used } \\
\text { by older adults to maintain closer contact with family and friends. } \\
\text { Even if they themselves did not own a computer, they will seek } \\
\text { one out in order to have it for communication purposes. }\end{array}$ \\
\hline 3. & $\begin{array}{l}\text { Problems with the small characters on keyboards found on cell } \\
\text { phones and remote control units discourages use of technology } \\
\text { that could potentially enhance the life style of the older adult. }\end{array}$ \\
\hline 4. & $\begin{array}{l}\text { In the opinion of the older adult, the focus of technology should be } \\
\text { to help keep their life simple. }\end{array}$ \\
\hline
\end{tabular}




\section{REFERENCES}

Brosnan, C., Upchurch, S., Meininger, J., Hester, L., Johnson, G., Eissa, M., 2005. Student nurses participate in public health research and practice through a school-based screening program. Public Health Nursing 22(3), 260-266

Burrows, D., Baillie, L., 1997. A strategy for teaching research to adult branch diploma students. Nurse Education Today 17(1), 39-45

Courtney, M., 2005. Evidence for nursing practice. Elsevier, Sydney.

Dirkx, J., 1997. Nurturing soul in adult learning. New Directions for Adult and Continuing Education 74, pp. 79-88

Gray, M., 2010. Research odyssey: the evolution of a research partnership between baccalaureate nursing students and practicing nurses. Nurse Education Today 30(4), 376-382. doi:10.1016/j.nedt.2009.10.001

Henderson, A., 2011. Leadership in clinical education: embedding learning in everyday practice. Nurse Education Today 31, 4-5. doi:10.1016/j.nedt.2010.01.003

Kolb, D., 1984. Experiential learning: Experience as the source of learning and development. Prentice Hall, New York.

McCaugherty, D., 1991. The use of a teaching model to promote reflection and the experiential integration of theory and practice in first-year student nurses: an action research study. Journal of Advanced Nursing 16(5), 534-543

McKinlay, A., Cowan, S., 2003. Student nurses' attitudes towards working with older patients. Journal of Advanced Nursing 43(3), 298-309

McLafferty, I., Morrison, F., 2004. Attitudes towards hospitalized older adults. Journal of Advanced Nursing 47(4), 446-453

McLaughlin, D., Freed, P., Tadych, R., 2006. Action methods in the classroom: creative strategies for nursing education. International Journal of Nursing Education Scholarship 3(1), 1-18

Nursing Council of New Zealand, 2007. Competencies for registered nurses. Available at: http://www.nursingcouncil.org.nz.

Perkins, E. R., 1992. Teaching research to nurses: Issues for tutor training. Nurse Education Today 12(4), 252-257

Ravert, P., Boyer, B., Harmon, K., Scoffield, H., 2004. Learning nursing research through faculty-mentored projects. Nurse Educator 29(4), 170-174

Rolfe, G., 1997. Beyond expertise: theory, practice and the reflexive practitioner. Journal of Clinical Nursing 6, 93-97

Schon, D., 1983. The reflective practitioner: How professionals think in action. Basic books, New York.

Schon, D., 1987. Educating the reflective practitioner. Jossey-Bass, San Francisco.

Taylor, S., Muncer, S., 2000. Redressing the power and effect of significance. A new approach to an old problem: Teaching statistics to nursing students. Nurse Education Today 20, 358-364

Tinto, V., Russo, P., 1994. Coordinated studies programs: their effect on student involvement at a community college. Community College Review 22, 16-26

Wood, P., 2002. Nursing's background of scholarly inquiry. In: Papps E. (Ed.), Nursing in New Zealand: Critical issues, different perspectives. Pearson Education, Auckland, NZ, pp. 40-51. 